\title{
Hemşirelik Öğrencilerinde Nazal Staphylococcus aureus Taşıyıcılığının Araştırılması
}

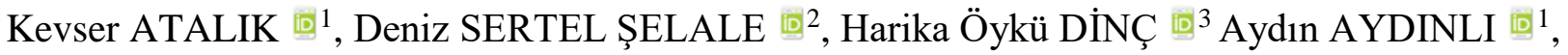 \\ Ülken Tunga BABAOĞLU ${ }^{4}$, Ayşe Demet KAYA ${ }^{1}$, Birsen YÜRÜGEN ${ }^{5}$
}

\section{ÖZ}

Amaç: Staphylococcus aureus ve Metisiline dirençli Staphylococcus aureus (MRSA) ile kolonize sağlık personeli ve sağlık alanında eğitim alan öğrenciler, hastane enfeksiyonları gelişimi açısından risk oluşturmaktadır. Nazal taşıyıcılı̆̆ın belirlenmesi ve önlenmesi, enfeksiyon kontrolünde önem taşımaktadır. Bu çalışmada, hemşirelik öğrencilerinin klinik stajlara başlamadan ve staj döneminde aktif olarak sağlık kurumlarında çalışırken nazal $S$. aureus taşıyıcılık durumları araştırılmıştır.

Gereç ve Yöntemler: Çalışmaya, 69'u birinci sınıfta, 60'ı ise üçüncü sınıfta eğitim görmekte olan toplam 129 hemşirelik öğrencisi dahil edilmiştir. Öğrencilerden alınan nazal sürüntü örnekleri koyun kanlı agar ve mannitol tuz agara ekilmiş ve bir gece inkübasyonu takiben, konvansiyonel yöntemler ile identifiye edilmiştir. Metisilin duyarllılı̆ı disk difüzyon yöntemi ile belirlenmiştir. İstatistiki analizde Pearson Ki-Kare testi kullanılmış ve istatistiksel anlamll1ık $\mathrm{p}<0,05$ olarak kabul edilmiştir.

Bulgular: Örneklerin mikrobiyolojik değerlendirilmesi sonucunda, klinik staj yapmakta olan öğrencilerden \%18,3; klinik staj yapmamış öğrencilerden ise $\% 14,5$ oranında S. aureus izole edilmiştir $(\mathrm{p}=0,556)$. MRSA taşıyıcıllğının ise, klinik staj yapmamış öğrencilerde \%10,1, staj yapmakta olan öğrencilerde \%1,6 oranlarında olduğu saptanmıştır $(\mathrm{p}=0,046)$.

Sonuç: Çalışma sonuçlarımız, her iki öğrenci grubunun S. aureus ve MRSA taşıyıcılığının genel populasyona benzer sınıllar arasında bulunduğunu, ancak MRSA taşıyıcılı̆̆ının klinikte staj yapmakta olan öğrencilerde diğer gruptan daha düşük olduğunu göstermektedir. Bu durumun, öğrencilerin halen devam etmekte olan eğitimleri sırasındaki edindikleri bilgi birikimleri ve mesleki uygulamalarında da bu bilgileri kullanmaları ile ilişkili olabileceği düşünülmektedir.

Anahtar Kelimeler: Staphylococcus aureus; MRSA; hemşirelik öğrencileri

\section{Investigation of Staphylococcus aureus Nasal Carriage in Nursing Students}

\begin{abstract}
Aim: Colonization of healthcare personnel and students studying in health sciences with Staphylococcus aureus and methicillin-resistant $S$. aureus pose a significant risk in the development of nosocomial infections. Detection and prevention of nasal carriage is crucial for infection control. In this study, S. aureus nasal carriage status was investigated in nursing students before and after starting clinical internships.

Material and Methods: A total of 129 nursing students, 69 of whom were in the first grade and 60 of whom were in the third grade, were included in the study. Nasal swabs were taken and inoculated on sheep blood agar and mannitol-salt agar, incubated overnight, and identified with conventional methods. Methicillin resistance was determined with disc diffusion method. Pearson Chi-Square test was used in statistical analysis and statistical significance was accepted as $\mathrm{p}<0.05$.

Results: Microbiological evaluation of the samples revealed S. aureus nasal carriage in $18.3 \%$ of students who have started clinical internships and $14.5 \%$ of students who haven't started clinical internships $(p=0,556)$. Nasal MRSA carriage rates were found to be $10.1 \%$ and $1.6 \%$, respectively $(\mathrm{p}=0,046)$.
\end{abstract}

1 İstanbul Okan Üniversitesi Tıp Fakültesi, Tıbbi Mikrobiyoloji Anabilim Dalı, İstanbul, Türkiye

2 İstanbul Sağlık ve Teknoloji Üniversitesi Eczacılık Fakültesi, Farmasötik Mikrobiyoloji Anabilim Dalı, İstanbul, Türkiye

3 Bezmiâlem Vakıf Üniversitesi Eczacılık Fakültesi, Farmasötik Mikrobiyoloji Anabilim Dalı, İstanbul, Türkiye

4 Kırşehir Ahi Evran Üniversitesi Tıp Fakültesi, Halk Sağlığı Anabilim Dalı, Kırşehir, Türkiye

5. İstanbul Okan Üniversitesi Sağlık Bilimleri Fakültesi, Hemşirelik Bölümü, İstanbul, Türkiye 
Conclusion: The results of our study demonstrate that nasal S. aureus and MRSA carriage of both student groups are between the normal limits defined for the general public, but the MRSA carriage rate was lower in the students who have started clinical internships than the other group. This situation is thought to be related to the knowledge accumulated by the students during their ongoing education and their use of this knowledge in their professional practice.

Keywords: Staphylococcus aureus; MRSA; nursing students

\section{GIRIŞ}

Staphylococcus aureus, insan vücudunun pek çok bölgesinde flora üyesi olarak bulunabilen firsatçı bir patojendir. $S$. aureus'un sağlık çalışanlarının deri ve burun mukozasında kolonize olması ile gelişen taşıyıcılık durumu, kişilerin potansiyel enfeksiyon kaynağı olması ve hastane epidemilerinde kilit rol oynaması ile önemlidir. $\mathrm{Bu}$ nedenle nazal $S$. aureus taşıyıcılığının belirlenmesi hastane enfeksiyonu kontrolünde önem taşımaktadır $(1,2)$.

S. aureus ve dirençli formu olan Metisiline dirençli Staphylococcus aureus (MRSA), hastane enfeksiyon etkenleri arasında ilk sıralarda yer almaktadır. Özellikle MRSA enfeksiyonları, MRSA suşlarında karşılaşılan çoklu ilaç direncinin tedavi seçeneklerini kısıtlaması nedeniyle önem taşımaktadır. Bu bakteriler hem toplum hem de hastane kaynaklı olabilmekte; sistemik ve lokal birçok enfeksiyona, hatta ölüme sebep olabilmektedir. MRSA ile enfekte kişiler arasında ölüm oranı, hasta popülasyonuna ve enfeksiyon bölgesine bağlı olarak \%560 arasında değişmektedir $(3,4)$.

Hastanede aktif çalışan sağlık personeline benzer şekilde, sağlık alanında eğitim alan öğrencilerin de enfeksiyonun epidemiyolojisinde rol oynayarak hem toplumda hem de hastane ortamında, $S$. aureus'un yayılmasında kaynak olabilecekleri düşünülmektedir $(5,6)$.

$\mathrm{Bu}$ çalışmada, İstanbul Okan Üniversitesi Sağlık Bilimleri Fakültesi Hemşirelik bölümü öğrencilerinde nazal S. aureus taşıyıcılığı araştırılmış ve öğrencilerin hastane ile ilişskilerinin taşıyıcılık oranına etkisinin gözlenmesi amaçlanmıştır.

\section{GEREÇ VE YÖNTEMLER}

Çalışmaya, İstanbul Okan Üniversitesi Sağlık Bilimleri Fakültesi Hemşirelik bölümünde eğitim almakta olan toplam 129 öğrenci dahil edildi. Çalışma grubunda bulunan 69 öğrenci birinci sınıf, 60 öğrenci ise üçüncü sınıf öğrencisiydi. Birinci sınıf öğrencileri klinikte hiç çalışmamış ve henüz Mikrobiyoloji eğitimi almamıştı. Üçüncü sınıf öğrencileri ise bir sene önce Mikrobiyoloji ve "Bulaşıcı hastalıklar hemşireliğì" dersleri almış ve klinik stajlara başlamış, aktif olarak sağlık kurumlarında çalışmaktaydı.

Çalışmaya alınacak öğrenciler, çalışma konusunda bilgilendirilmiş ve her öğrenciden bilgilendirilmiş onam alınmıştır. Çalışma Helsinki Bildirgesine uygun olarak yürütülmüş ve çalışma için Okan Üniversitesi Etik Kurulundan onay alınmıştır (19.02.2018 tarih, 91 no).

Çalışmada Hemşirelik bölümünde eğitim gören 129 öğrenci klinik stajı yapmakta olan ve staj yapmamış öğrenciler olmak üzere iki gruba ayrılmış ve tüm katılımcılardan eş zamanlı olarak nazal sürüntü örnekleri toplanmıştır.

Toplanan nazal sürüntü örnekleri $\% 5$ koyun kanlı agara (RTA Labs, Türkiye) ekilerek, $37^{\circ} \mathrm{C}$ 'de 24 saat inkübe edilmiştir. Üreyen bakteriler koloni morfolojisi bakımından değerlendirilmiş ve $S$. aureus şüpheli kolonilerin identifikasyonu Gram boyama, katalaz testi, koagülaz testi ve mannitol fermentasyon testiyle yapılmıştır. Koagülaz varlığı ticari bir lateks aglütinasyon testi olan Staphylase test kiti (Oxoid Limited, England) ile gösterilmiştir. Katalaz ve koagülaz testleri pozitif olup, Mannitol Salt agar'da sarı zon oluşturarak üreyen stafilokoklar, S. aureus olarak yorumlanmıştır.

İzole edilen $S$. aureus suşlarının metisilin duyarlılığı, European Committee on Antimicrobial Susceptibility Testing (EUCAST) standartlarına göre Muller Hinton agar'da (RTA Labs, Türkiye) disk difüzyon yöntemi ile incelenmiştir (7). Bakteri suşlarının metisilin direnci sefoksitin $(30 \mu \mathrm{g})$ diski (Oxoid) kullanılarak araştırılmış ve sonuçlar EUCAST kriterleri doğrultusunda değerlendirilmiştir.

\section{İstatistiksel Analiz}

İstatistiksel değerlendirme, SPSS 21.00 paket programı kullanılarak yapılmıştır. Kategorik veriler sayı ve yüzde olarak sunulmuştur. Kategorik veri analizinde Pearson Ki-Kare testi uygulanmıştır. İstatistiksel anlamlılık $\mathrm{p}<0,05$ olarak kabul edilmiştir.

\section{BULGULAR}

Çalışmaya katılan 129 hemşirelik öğrencisinin 60’1 klinik staj yapmakta iken; 69'u ise hiç klinik staj yapmamıştı.

Örneklerin değerlendirilmesi sonucunda klinik staj yapmakta olan 60 öğrencinin 11'inden $(\% 18,3)$; klinik staj yapmamış 69 öğrencinin ise 10'undan (\%14,5) S. aureus izole edildi (Tablo 1). S. aureus oranı her ne kadar staj yapan öğrencilerde daha yüksek bulunsa da aradaki fark istatistik olarak anlamlı değildi $(\mathrm{p}=0,556)$.

Gruplar MRSA taşıyıcılığı açısından incelendiğinde, klinik staj yapmamış öğrencilerdeki taşıyıcılık oranının $\% 10,1$, staj yapmakta olan öğrencilerdeki oranın ise \%1,6 olduğu saptand. Gruplar arasındaki fark istatistiksel olarak anlamlı bulundu $(\mathrm{p}=0,046)$.

Tablo 1. Hemşirelik Öğrencilerinde S. aureus Taşıyıcılığı ve Metisiline Direnç Durumları

\begin{tabular}{|l|c|c|c|}
\hline Grup & Toplam & S. aureus & MRSA \\
\hline $\begin{array}{l}\text { Staj yapmakta } \\
\text { olan ögrrenciler }\end{array}$ & 60 & $11(\% 18,3)$ & $1(\% 1,6)$ \\
\hline $\begin{array}{l}\text { Staj yapmayan } \\
\text { ŏgrenciler }\end{array}$ & 69 & $10(\% 14,5)$ & $7(\% 10,1)$ \\
\hline Toplam & 129 & $21(\% 16,3)$ & $8(\% 6,2)$ \\
\hline
\end{tabular}

\section{TARTIŞMA}

Metisiline dirençli S. aureus'nın etken olduğu enfeksiyonlar, hastane ile ilişkili (HA-MRSA) ve toplumla ilişkili (CA-MRSA) olmak üzere ikiye ayrılmaktadır. Toplumda sağlıklı bireylerde, MRSA kolonizasyonu saptandığı gibi, sağlık çalışanları da MRSA taşıyıcılığı geliştiğinde hastane ilişkili MRSA enfeksiyonlarında kilit rol oynamaktadır. MRSA, hastane kaynaklı enfeksiyonların önde gelen nedenlerinden biridir (3). 
Ülkemizde yapılan çalışmalar, toplumda görülen $S$. aureus taşıyıcılık oranlarının \%7-39, MRSA taşıyıcılık oranlarının ise $\% 0,3-8,7$ arasında değiştiğini göstermektedir (8-12). Sağlık çalışanlarında ise bu oranlar sirasiyla $\% 24$ ve $\% 16$ olarak bildirilmiştir (13). Sağlık çalışanlarının $S$. aureus ve MRSA taşıyıcısı olması, hastane kaynaklı enfeksiyonlarda kaynak rolü oynayarak, hastalar için potansiyel tehlike oluşturmaları yönü ile önem taşımaktadır ${ }^{5}$. S. aureus ve MRSA taşıyıcılığı açısından değerlendirildiğinde, sağlık kurumlarında eğitim alan öğrencilerde de sağlık çalışanlarına benzer şekilde normal populasyondan daha yüksek oranlarda taşıyıcılık saptanmaktadır (14). Yapılan çalışmalarda elde edilen veriler farklılık göstermektedir. Ülkemizden Gündüz ve arkadaşları (14) çalışmalarında, sağlık yüksek okulu öğrencilerinden klinik staj dönemi öncesinde ve sonrasında aldıkları nazal sürüntü örneklerini incelemiş ve nazal $S$. aureus taşıyıcılık oranını klinik staj öncesinde $\% 5,5$; staj sonrasında ise $\% 11,8$ olarak bildirmişlerdir.

Akpınarve arkadaşlarıları (15), 66 hemşirelik öğrencisinin staj öncesi dönemde hiçbirinde MRSA kolonizasyonu saptamazken, klinik maruziyet sonrasında 4 (\%6,1) öğrencide MRSA kolonizasyonu geliştiğini bildirmişlerdir. MSSA kolonizasyonu ise staj öncesinde $\% 13,6$; staj döneminde \%18,2 olarak bulunmuştur.

Erciyes Üniversitesi'nde yapılan bir başka çalışmada, Ebelik-Hemşirelik bölümü öğrencilerindeki nazal $S$. aureus taşıyıcılık oranı, stajyer öğrencilerde $\% 5,9$, stajyer olmayan öğrencilerde ise $\% 4,8$ olarak saptanmıștır. İzole edilen altı $S$. aureus suşunun sadece birinde $(\% 16,7)$ metisiline direnç tespit edilmiştir (16).

Ülkemizde yapılan sınırlı sayıdaki çalışma incelendiğinde, klinikte staj yapma ile $S$. aureus taşıyıcılık oranları arasında bir ilişki saptandığı görülmektedir ancak bizim çalışmamızda böyle anlamlı bir ilişki görülmemiştir. Ayrıca MRSA oranları açısından değerlendirildiğinde, çalışma sonuçlarımızın diğer çalışmalardan farklı olduğu ve staja başlamamış öğrencilerdeki MRSA oranının daha yüksek bulunduğu görülmektedir.

Hem dünyada hem de ülkemizde yapılan çalışma sonuçları değerlendirildiğinde, $S$. aureus ve MRSA taşıyıcılık oranlarının yaşanılan coğrafyaya, populasyona ve hastaneye göre farklılık gösterdiği anlaşılmaktadır.

Kim ve arkadaşları (17) Kore'de yaptıkları bir çalışmada ise, klinik deneyimi bulunan 215 hemşirelik öğrencisinden alınan nazal örnekleri incelemiş ve 62 öğrencide $(\% 28,8)$ S. aureus taşıyıcılı̆̆ 3'ünde $(\% 1,4)$ MRSA varlığı saptamışlardır.

Hindistan'da yapılan bir çalışmada, klinikte staj yapan 119 hemşirelik öğrencisi ve klinik maruziyeti bulunmayan 100 eczacılık öğrencisinin $S$. aureus taşıyıcıllk oranları sırasıyla \%36 (n:36) ve \%34 (n:34) olarak saptanmıştır. Klinikteki hemşirelik öğrencilerinin \%9,2'si MRSA taşıyıcısı iken klinikle ilişkisi olmayan eczacılık öğrencilerinde bu oran $\% 4$ olarak saptanmıştır ve MRSA taşıyıcılığı açısından aradaki fark istatistiksel olarak anlamlı bulunmamıştır (18).

Rohde ve arkadaşlarının (19) A.B.D.'de yaptıkları çalışmalarında ise, 87 hemşirelik öğrencisinin klinik rotasyonları boyunca nazal $S$. aureus kolonizasyonunun stabil kaldığı (\%17-26) ve MRSA kolonizasyonunun ise artmadığı bildirilmiştir. Araştırmacılar bu sonuçların, öğrencilere çalışmanın başında MRSA konusunda bilgilendirme yapılmış olmasından kaynaklanabileceğini düşünmüşlerdir. Bizim çalışmamızın başlangıcında bu tip bir eğitim verilmemiştir ancak stajyer öğrenciler bir önceki eğitim döneminde "Bulaşıcı hastalıklar hemşireliğgi” ve "Mikrobiyoloji” dersleri almıştır. Sağlık çalışanı eğitiminin, hastane enfeksiyonlarının kontrolünde temel oluşturduğu bilinen bir gerçektir. Ülkemizde Özyürek ve arkadaşları (20), hemşireler ve hemşirelik öğrencileri ile yaptığ karşılaştırmalı bir çalışmada, 3. ve 4. sınıfta bulunan hemşirelik öğrencilerinin \%93'ünün, hemșirelerin ise \%59,2'sinin MRSA hakkında bilgi sahibi olduğunu bildirmiştir. Ayrıca aynı çalışmada çalışma yılı arttıkça öğrenilen bilgilerin unutulduğu saptanmıştır. Bu bilgilerin 1şığında biz de çalışmamızdaki stajyer öğrencilerin geçmiş dönemde aldıkları derslerde edindikleri bilgilerin, staj yaptıkları kurumlarda pratik uygulamalarla pekişerek bilgi ve bilinç düzeylerini artırmış olduğunu ve çalışmamızdaki düşük taşıyıcılık oranları üzerinde etkisi olabileceğini düşünmekteyiz. Ayrıca öğrencilerin eğitimlerinin, staj yaptıkları sağlık kurumlarında uygulamalı olarak devam ediyor olması nedeniyle öğrencilerin gözlemlendiklerini bilmelerinin de enfeksiyon etkenleri konusunda daha dikkatli davranmalarına neden olabileceği düşüncesindeyiz.

Carvalho ve arkadaşları (21), Brezilya'da yaptıkları çalışmalarında 47'si hastalarla direkt ilişkisi olmayan ve 91'i hastalar ile direkt ilişkili toplam 138 hemşirelik öğrencisinin $30(\% 21,7)$ 'unda nazal $S$. aureus taşıyıcılığı saptamıştır. Hastalarla direkt ilişki içinde olan 91 öğrencinin $18(\% 19,7)$ 'inde nazal S. aureus taşıyıcılı̆̆ belirlenirken; herhangi bir sağlık biriminde staj yapmamış 47 öğrencinin $12(\% 25,5)$ 'sinin S. aureus taşıyıcısı olduğu saptanmıştır.

Her ne kadar klinik maruziyeti bulunan hemşirelik öğrencilerinin MRSA taşıyıcılık oranlarının daha yüksek bulunduğu pek çok çalışmada bildirilmişse de, Rohde ve Carvalho'nun çalışmalarında olduğu gibi klinik ilişkili hemşirelik öğrencilerinde MRSA oranlarının artmadığı ve hatta klinik ilişkisi bulunmayan öğrencilerde daha yüksek olduğu çalışmalar da bulunmaktadır $(19,20)$. Bizim çalışmamızda da benzer şekilde klinikte staj yapmamış öğrencilerde MRSA oranı daha yüksek saptanmıştır.

\section{SONUC}

Çalışma sonuçlarımız değerlendirildiğinde, her iki ögrenci grubunun $S$. aureus ve MRSA taşıyıcılığı normal popülasyona benzer sınırlar arasında bulunmuştur. MRSA taşıyıcılığının klinikte staj yapan öğrencilerde diğer gruptan daha düşük olmasının, öğrencilerin eğitimleri sırasında aldıkları mikrobiyoloji, enfeksiyon hastalıkları ve epidemiyoloji gibi derslerin sağladığı bilgi birikimi ile ilişkili olabileceğini; stajyer öğrencilerin enfeksiyon kontrol protokollerini bilmeleri ve gözlemlendiklerini bildikleri için bu protokollere sıkı bir şekilde uymalarından kaynaklandığını düşünmekteyiz. Ayrıca hemşire ve hemşirelik öğrencileri arasında $S$. aureus ve MRSA taşıyıcılık oranlarının, bilgi ve bilinç düzeylerinin belirlenmesine yönelik yapılacak karşılaştırmalı çalışmaların, çalışmamız ve benzer 
çalışma sonuçlarını yorumlamada yol gösterici olduğunu düşünmekteyiz.

\section{KAYNAKLAR}

1. Botelho-Nevers E, Gagnaire J, Verhoeven PO, Cazorla C. Decolonization of Staphylococcus aureus carriage. Medecine et Maladies Infectieuses. 2017; 47(5): 305-10. https://doi.org/10.1016/j.medmal. 2016.10.005

2. Sakr A, Bregeon F, Mege JL, Rolain JM, Blin O. Staphylococcus aureus nasal nolonization: An update on mechanisms, epidemiology, risk factors, and subsequent infections. Front. Microbiol. 2018; 9: 2419. https://doi.org/10.3389/fmicb.2018.02419

3. Siddiqui AH, Koirala J. Methicillin resistant Staphylococcus aureus. In: StatPearls [Internet]. Treasure Island (FL): StatPearls Publishing; 2021 Jan-. PMID: 29489200. Available from: https://www.ncbi.nlm.nih.gov/books/NBK482221/.

4. Ansari S, Jha RK, Mishra SK, Tiwari BR, Asaad AM. Recent advances in Staphylococcus aureus infection: focus on vaccine development. Infection and Drug Resistance. 2019:12 1243-55.

5. Conceicao T, de Lencastre H, Aires-deSousa M. Carriage of Staphylococcus aureus among Portuguese nursing students: A longitudinal cohort study over four years of education. PLoS ONE. 2017; 12(11): $\mathrm{e} 0188855$.

6. Fascia P, Martin I, Mallaval FO, Grattard F, Pozzetto B, Luncht F, Berthelot P. Implication potentielle d'étudiants infirmiers dans la transmission de Staphylococcus aureus résistant a la ethicilline lors d'une epidemie nosocomiale. Pathologie Biologie 2003; 51: 479-82.

7. EUCAST Klinik ve/veya epidemiyolojik önemi olan direnç mekanizmaları ve direnç özelliklerini saptama kılavuzu. Version 2.0 July 2017. p:29-31.

8. Erdoğan H, Arslan H. Otel personelinin burun ve boğaz kültüründe staphylococcus aureus taşıyıcılığının araştırılması ve risk faktörlerinin irdelenmesi. Klimik Derg. 2011; 24(2): 90-3.

9. Çakır D. Çocuklarda toplum kökenli metisiline duyarlı ve metisiline dirençli staphylococcus aureus taşıyıcılık sıklığı ve risk faktörleri. (Uzmanlık tezi) Bursa: Uludağ Üniversitesi Tıp Fakültesi; 2012.

10. Garipcin M, Şeker E. Nasal carriage of methicillinresistant Staphylococcus aureus in cattle and farm workers in Turkey. Vet. Archiv. 2015; 85: 117-29.

11. Baş Öncül A. Toplumda ve hastanede edinilmiş nazal stafilokok taşıyıcılığında risk faktörleri ve direnç durumlarının karşılaştırılması. (Uzmanlık tezi) İstanbul:T.C. Sağlık Bakanlığı Şişli Etfal Eğitim ve Araştırma Hastanesi; 2006.

12. Özkütük A, Özdemir S, Ergon MC, Yuluğ N. Askeri personelde metisiline dirençli Staphylococcus aureus burun taşıyıcılığı prevalansı. İnfeksiyon Derg. 2003; 17 (3): 285-7.

13. Akpınar O, Yiğit A, Güzel M, Akdoğan D. The investigation of nasal carriage rate of methicillinresistant Staphylococcus aureus among Turkish healthcare workers, 1990-2019: meta-analysis. Turk Hij Den Biyol Derg. 2020; 77(2): 217-26.
14. Gündüz T, Akgül A, Aktaş E, Saçar T. Sağlık yüksek okulu öğrencilerinde nasal Staphylococcus aureus taşıyıcılığı. Pamukkale Tıp Dergisi. 2008; 1(2): 82-3.

15. Akpınar RB, Celebioglu A, Uslu H, Uyanık MH. An evaluation of the hand and nasal flora of Turkish nursing students after clinical practice. Journal of Clinical Nursing. 2008; 18: 426-30. https://doi.org/10.1111/j.1365-2702.2008.02514.x

16. Oğuzkaya Artan M, Çürük GN. Ebelik-hemşirelik öğrencilerinin burunlarında metisiline dirençli staphylococcus aureus kolonizasyonunun araştırılması. Türk Mikrobiyol Cem Derg. 2005; 35: 16-9.

17. Kim OS, Yim J, Jeon MY. Rates of Staphylococcus aureus and methicillin-resistant Staphylococcus aureus nasal carriage infections among nursing students. International Journal of Bio-Science and Bio-Technology. 2015; 7(5): 21-32.

18. Krishnamurthy V, Saha A, Renushri BV, Nagaraj ER. Methicillin resistant Staphylococcus aureus carriage, antibiotic resistance and molecular pathogenicity among healthy individuals exposed and not exposed to hospital environment. J Clin Diagn Res. 2014; 8(7): DC04-DC8.

19. Rohde RE, Patterson T, Covington B, et al. Staphylococcus, not MRSA? A final report of carriage and conversion rates in nursing students. Clin Lab Sci. 2014; 27(1): 21-31.

20. Özyürek P, Bulantekin Ö. Hemşire ve hemşirelik bölümü öğrencilerinin MRSA'lı hastaya klinik yaklaşımlarının değerlendirilmesi. Kocatepe Tip Derg. 2008; 9: 21-32.

21. Carvalho SM, Andrade DFR, Sousa AFL, Costa Valle ARM, Freitas DRJ, Nascimento GC, et al. Nasal colonization with Staphylococcus aureus in nursing students: ground for monitoring. Rev Bras Enferm [Internet]. 2016; 69(6): 984-9. 